\title{
Renminbi Revaluation, Euro Appreciation and Chinese Markets: What Can We Learn From Data?
}

Paul D. McNelis
Fordham University

Salih N. Neftçi

City University of New York

Follow this and additional works at: https://fordham.bepress.com/crif_working_papers

Part of the Finance and Financial Management Commons

\section{Recommended Citation}

McNelis, Paul D. and Neftçi, Salih N., "Renminbi Revaluation, Euro Appreciation and Chinese Markets: What Can We Learn From Data?" (2006). CRIF Working Paper series. 4.

https://fordham.bepress.com/crif_working_papers/4 


\title{
Renminbi Revaluation, Euro Appreciation and Chinese Markets: What Can We Learn From Data?
}

\author{
Paul D. McNelis* \\ Fordham University \\ Hong Kong Institute for Monetary Research \\ and \\ Salih N. Neftçi ${ }^{\dagger}$ \\ City University of New York
}

January 2006

\begin{abstract}
This paper examines financial market data to assess the likelihood of renminbi revaluation and its implications for Chinese share price increases, given the continuing appreciation of the Euro against the U.S. dollar. We find that the 3-month non-deliverable forward premia are key series linking these variables. The forward premia predict series A share-price changes, while Euro/US dollar exchange rates in turn predict foreward-premia. Bayesian models outperform standard linear models for forecasting performance.
\end{abstract}

JEL Classification: G14, G15, G18

Keywords: Prediction, Bayesian forecasting, Granger tests of causality, nested models

* Department of Finance, Fordham University, Lincoln Ceter Campus, New York, N.Y. 10023. Email: mcnelis@fordham.edu.

$\dagger$ Department of Economics, Graduate Center, CUNY, New York. Email: sneftci@wwc.com

The views expressed in this paper are those of the authors, and do not necessarily reflect those of the Hong Kong Institute for Monetary Research, its Council of Advisors, or the Board of Directors. 


\section{Introduction}

This paper takes up the following question: what can we learn about prospects of Renminbi (RMB) revaluation as well as Chinese share-market appreciation from daily financial market data? More specifically, how much does the sharp appreciation of the Euro against the US dollar explain these developments? Do interest-rate differentials matter, or should we pay more attention to Non- Deliverable Forward (NDF) premia and discounts for understanding how changes in the Euro are linked to Chinese financial markets and to the likelihood of RMB revaluation?

The appreciation of the Euro (or decline of the US dollar) reflects differences in the United States and Euro Area macroeconomic fundamentals. While the RMB is linked to the US dollar, the fundamentals of the Chinese economy are very different from the fundamentals of the United States. Thus we may expect that the effects of Euro appreciation will have different consequences in China than in the United States. Given these differences, there are strong pressures for the Chinese to revalue their currency. Fred Bergsten, for example, notes that China continues to "strengthen its competitiveness" by "riding the dollar down", which in turn "severely truncates the adjustment process" because "other Asian countries fear losing competitiveness against China and thus block their appreciations against the dollar" [Bergsten (2004), p.13]. Bergsten argues that RMB revaluation would "help China cool its overheated economy" and help stop the inflow of speculative capital [Bergsten (2004), p.13].

Of course, there are other views on this matter coming from the Pacific region. For example, Lau, Mo and $\mathrm{Li}$ (2004) of the Hong Kong Monetary Authority argue that a modest RMB revaluation would not necessarily dampen down speculative capital flows, but rather invite renewed speculative inflows on the expectation of further strengthening of the currency. They point out that job creation and financial stability are the key priorities and RMB revaluation may in fact do more harm than good. They also note that a reduction in Chinese competitiveness with the United States, through RMB revaluation, would actually reduce exports of many Asian countries, since China imports many of its raw materials from these countries as inputs for industrial exports to the United States and other developed countries [Lau, Mo and Li, (2004), p.4].

We do not, of course, assess the merits of these arguments for or against RMB revaluation. Given these strong differences of opinion, reflecting not only economic logic but also political factors, it is safe to say the RMB revaluation is considered by financial markets to be a "plausible event", and as Neftçi (2004) points out, there will be positions taken in favor or against its occurrence. These positions, in turn, may create significant exposures, with the result that balance sheets may have new currency and maturity mismatches [Neftçi, (2004), p.2]. Furthermore, understanding the way these exposures are put together (the instruments used and the way they are structured) is crucial for correct measurement and monitoring of the risks involved in the event or non-event of RMB revaluation.

The main results show that interest rate differentials between China and the United States as well as the series "A" share prices respond to the non- deliverable forward premia but that there is no evidence of reverse feedback. Interest-rate differentials matter neither for the small movements of the RMB, nor for the share price increases. The Euro/dollar exchange rate has strong direct effects on the NDF premia, which in turn affect interest differentials and the share markets. Finally, Bayesian vector autoregressive 
(BVAR) methods, which detect the significant causal effect of the Euro/dollar rate on the NDF premia and the effects of NDF premia on share prices, perform much more accurately than the standard vector autogressive (VAR) methods. They also show significant causal effects of the euro/dollar rate on the NDF with out-of-sample Granger tests of causality.

The next section describes the data we use for our estimation, while the third section describes recent developments in Chinese foreign exchange (FX) markets, and Section 4 puts forward the central hypothesis of this paper, with a simple model. Section 5 describes the benchmark linear and Bayesian VAR specifications, while Section 6 examines the results of the estimation of the two models on the basis of in-sample diagnostics, in-sample Granger tests of causality, and the impulse-response paths generated by a change in the Euro/US Dollar exchange rate. Section 7 takes up forecasting performance of the two competing models, as well as Granger out-of-sample tests of causality with the BVAR model. The last section concludes.

\section{Data}

Although the Reminbi/US dollar exchange rate is officially fixed, there are small daily movements, as Figure 1 shows.

The relationship between the interest differentials and the prices of the 3-month non-deliverable forward premia appears in Figure 2.

The movement of the two series of share prices appears in Figure 3. We see that there is a strong co-movement of both series until the later part of 2003 , when the Series A price moved upward very sharply, then fell sharply, while the Series A price movements were less sharp.

The movement of the Euro appears in Figure 4. We see a steady appreciation of the Euro during this two-year period. More importantly, we also see that periods of abrupt movements in this series appear to be correlated with swings in the share prices and interest differentials.

Overall, we see a regime change taking place in the data after July 2003. When the Euro begins its increase against the dollar, we see the upsurge in the Series A share price index as well as increased volatility in the interest rate differentials and in the nondeliverable forward premia.

\section{Foreign Exchange Market in China}

It is often not realized that China has already introduced significant flexibility in foreign exchange operations, when compared with the early days of reform (1979-93). In many ways, RMB convertibility for current account transactions is similar to those that exist in OECD countries. RMB is not convertible for capital account transactions, but a significant amount of flexibility has been introduced here as well. 
Early reforms have eliminated the existence of multiple or dual exchange rates, and have unified the settlement and sale of foreign exchange (FX). A unified inter-bank market in FX was established. ${ }^{1}$

The China Foreign Exchange Trade Center (CFETC) in Shanghai is a PBoC directed non-profit entity. It is based upon membership, and it has more than 1000 members as of 2004 . These members are made up of Chinese banks, foreign banks and other non-bank financial institutions. The CFETC deals only with cash trades and members cannot take proprietary positions. It plays the role of a unified, nationwide spot FX market in China. PBoC directly runs the operations and controls the RMB exchange rate movements in the Center. [See Zhang (2004)].

NDF operations can be conducted on the RMB, and this is known. ${ }^{2}$ Less well known is the existence of forward RMB contracts. The Bank of China has been allowed for the last 8 years to trade RMB forwards. Recently other large Chinese banks were given the right to trade such contracts as well. However, the Bank of China's dominating position in this market persists. Domestic and some foreign financial institutions are allowed to trade in this market for hedging purposes. ${ }^{3}$

It is relatively easy, given these markets and the related reforms, to take speculative positions of the Chinese RMB. In fact, the high transactions costs, lower transparency and limited liquidity of RMB NDFs make these instruments and the Yuan forwards a less than economical way of taking such positions. Asset swaps, equity swaps and currency swaps may be much more economical in this respect. It is quite likely that such instruments are used more and more in these speculative positions. However, it is quite difficult to obtain such data on these over-the-counter (OTC) deals. The Yuan NDFs, on the other hand, are quoted in Reuters and daily data are available. Although they may not be cost effective instruments, the NDF quotes are still an excellent proxy for the speculative sentiment that exists in the NDF market. For this reason, we make use of this for investigating the dynamics of the RMB exchange rate and the underlying speculative sentiment.

\section{A Hypothesis}

For simplicity we formulate the hypothesis in terms of China, the USA and Europe. We abstract from most of the reality and consider a simple macro model that describes the "current" macroeconomic conditions for the US economy.

The US Federal Reserve (FED) is assumed to target interest rates $r_{t}$, so that

$$
r_{t}=r_{0}
$$

1 The FX market is administered by the State Administration of Foreign Exchange (SAFE), which is part of the People's Bank of China (PBoC) structure. SAFE has 294 center branch offices and 487 smaller branch offices in China. For details of this and related issues see Zhang (2004).

2 The Chinese NDF market started in Hong Kong during the mid 1990s. During most of the 1990s market players felt that there was a risk of a Renminbi devaluation and they wanted to hedge their operations in China. Expectations of a revaluation appeared after 2002 and the RMB NDF market started to be better known. The RMB NDFs settle according to the 4:00pm value of the State Administration of Exchange Control (SAEC) rate as announced in Reuters page CNY.

3 The traded forward contract has 14 tenors. There is an initial margin and the positions are marked to market. Yet, the market has been rather thin, mainly due to limits and restrictions on the participation of financial institutions. 
We omit the time subscripts and write,

$$
r_{o}=f\left(\frac{M}{p}\right), f^{\prime}<0
$$

where $M$ is money supply and $p$ is the price level. The demand side, where $y^{d}$ is the real demand, is given by

$$
y^{d}=g(r, W)
$$

where $W$ is real wealth. The growth of real wealth is assumed to be exogenous.

The interesting part of the argument relates to aggregate supply $y^{s}$ and to imports $\mathrm{im}$. We assume that the Chinese economy can provide unlimited amount of imports at a constant price to the US economy. The USD-RMB rate denoted by $e_{t}$ and the Chinese price level $p^{c}$ are assumed to be constant. ${ }^{4}$ Thus we have:

$$
y^{d}=y^{s}+i m
$$

Here $i m$ should be considered as a residual and $y^{s}$ as a constant.

The main point of this model is that the Chinese economy sets the exchange rate $e_{t}$ and the $p^{c}$ so as to provide unlimited imports to the US economy at a constant price, $p^{c} / e_{t}$. As the FED maintains an environment of low interest rates and real wealth appreciation, the real demand in the US is met by higher and higher imports from China.

The implications of such a (temporary) equilibrium are,

1. continuing, and growing United States current account deficits;

2. the appearance that such deficits are more sustainable than previously imagined;

3. absence of any significant United States inflation, since we need to have

$$
p=\frac{p^{c}}{e}
$$

4. continuously "low" interest rates in the US economy;

5. the (medium-term) sustainability of real wealth expansion and increases in US asset prices ${ }^{5}$; and

4 the ignores the recent worries about an increased Chinese inflation. However, we think that this is of secondary importance within the present context.

5 The existence of credit lines will restrict the size of arbitrage positions the players may take. This will make it possible for "carry trade" or "relative value" positions to continue longer than a typical macro model may envision. 
6. it will at the same time require continuous capacity expansion in China, to meet the demand for imports in the United States.

The continuing sustainability of the US current account deficit with respect to China has also been argued by Dooley, Folkerts-Landau and Garber (2004). In fact, they call this deficit not only sustainable but an intergral feature of a sustainable international monetary system. Through the deficit, the United States supplies international collateral to China, which in turn supports two-way trade in financial assets, which liberates capital formation in China from inefficient domestic markets.

A major feature of this paradigm is its effect on Europe. We do not model this component, but under the paradigm described here the US Dollar may very well depreciate against the Euro due to larger and larger current account deficits. This will force the RMB to depreciate against the Euro by the same amount and will make Chinese exports more and more competitive against European export sectors.

The major hypothesis that we would like to test in this paper relates to this last point. We claim that as the US dollar depreciates against the Euro, Chinese goods would become increasingly more competitive in Europe. ${ }^{6}$ This will have two implications. First the depreciation in the US Dollar has a limited effect on the US current account since US exports do not necessarily become as com-petitive as expected, due to the simultaneous depreciation of the RMB. Second, the European economy, which does not "benefit" from asset price appreciation, suffers. This increasingly puts pressures on the RMB for revaluation, which, we assume, is captured by the NDF discount.

According to this hypothesis, the time series data should show the Euro/US Dollar as the main determinant of the NDF discount observed in the RMB NDF market. The effects of interest rates and the RMB exchange rates should be limited. We test this hypothesis in the sections below.

\section{VAR and Bayesian VAR Methodology}

We use two models: the benchmark linear vector autoregressive (VAR) model, and the alternative Bayesian vector autoregressive model (BVAR).

For the VAR, we use the familiar specification

$$
\begin{aligned}
& Y_{t}=X_{t} \beta+\epsilon_{t} \\
& \epsilon_{t} \sim N(0, \Sigma) \\
& \Sigma=\left[\begin{array}{c}
\sigma_{1}^{2} 0 \ldots \ldots .0 \\
0 . \sigma_{2}^{2} 0 \ldots .0 \\
0 \ldots \ldots \ldots \sigma_{G}^{2}
\end{array}\right]
\end{aligned}
$$

where the matrix $X$ includes lagged values of the matrix $Y_{t}$, which is dimension 1 by $G$, while $X$ is dimension 1 by $K$ and $\beta$ is dimension $K$ by $G ; \epsilon$ is 1 by $G$, while the time-invariant variance-covariance matrix $\Sigma$ is a diagonal matrix.

6 And of course, in Japan, South Korea etc... 
As noted years ago by Litterman (1986), estimation of such VAR models suffer from overparameterization, leading to multicollinearity problems as well as reduced out-of-sample performance. If we are interested in Granger tests of causality based on F statistics, we need a large number of lags to remove serial dependence.

The Bayesian approach is to specify "fuzzy" restrictions on the coefficients of the VAR model, rather than zero exclusion restrictions, or assumptions about the shape of the lag coefficients, as in geometrically declining weights. This is an alternative to the "all or nothing" approach of dropping lags completely, in order to save on degrees of freedom. The idea is that coefficients on longer lags are more likely to be closer to zero than coefficients on short lags. However, in Bayesian estimation, the data are permitted to override this prior if the empirical evidence to the contrary about a coefficient is strong. The idea is to impose on the longer lags prior normal distributions with means of zero and progressively smaller standard deviations. We use Theil's mixed estimation technique for obtaining $\widehat{\beta}$ for equation $g$ :

$$
\begin{gathered}
Y_{g, t}=X_{t} \beta^{g}+\epsilon_{g, t} \\
R \beta^{g}=r+v \\
\epsilon_{g, t} \sim N\left(0, \sigma_{g}^{2}\right) \\
v \sim N\left(0, \lambda^{2} I\right) \\
\widehat{\beta}^{g}=\operatorname{inv}\left(X^{\prime} X+k R^{\prime} R\right) \cdot\left(X^{\prime} Y_{g}+k R^{\prime} r\right) \\
k=\lambda^{2} / \sigma_{g}^{2}
\end{gathered}
$$

The estimation involves the choice of hyperparameters governing the estimation of $\widehat{\beta}^{g}$ : The vector $r$, for the priors of the coefficients for each of the $g$ dependent variables, is assumed to be a vector set at $\gamma$ for the first lag and zero for all of the others, for the lags of $Y_{g}$

$$
r=\left[\begin{array}{l}
\gamma \\
0 \\
\cdot \\
\cdot \\
0
\end{array}\right]
$$

For the lags of the other dependent variable, we set the mean at zero. We call this specification a Monte Carlo Markov Chain (MCMC) prior, since only the first lag of the dependent variable enters with a unitary coefficient while all other lags are zero.

Similarly, the matrix $R$ is normalized so that $\lambda$ is the standard deviation of the coefficient of the first lag of the dependent variable. Given this specification, the standard deviations (around a zero mean) in the lag distributions decrease in a harmonic manner. Thus the coefficients on lags $\ell=2, \ldots \ell^{*}$ are given prior normal distributions with standard deviations $\lambda / \ell^{-\delta}$, where $\delta$ represents a decay hyperparameter. Furthermore, the standard deviations on the lags of variables other than the dependent variable are tightened around zero, at all lags, by a factor $\theta$, called the "shrinkage parameter". 
The matrix $R$ has the following specification:

$$
\begin{aligned}
R & =\frac{\lambda}{\delta_{i j}^{\ell}} \\
\delta_{i, j}^{\ell} & =\frac{\lambda}{\ell^{-\delta}}, \text { for } i=j \\
& =\frac{\theta \lambda \widehat{\sigma}_{i}}{\ell^{-\delta} \cdot \widehat{\sigma}_{j}}, \text { for } i \neq j
\end{aligned}
$$

Following Litterman (1986), the parameters $\widehat{\sigma}_{i}$ and $\widehat{\sigma}_{j}$ are obtained for dependent variables $Y_{i}$ and $Y_{j}$ by univariate regressions of each variable on a liberal number of lags and a constant term. Litterman also notes that a gain in efficiency can be obtained by estimating all equations together, in a Regression of Seemingly Unrelated Equations (RESURE) method. He does not recommend this, because of the increased computational burden.

Hamilton (1994) points out that for many series, such as first-differences, the natural prior might be a white noise, with $\gamma=0$, rather than a unit root autoregression, with $\gamma=1$; as Litterman suggests. Hamilton also points out that there is need for seasonal adjustment in order to use these priors [Hamilton (1994), p. 362]. In our transformation of the daily data, to remove "calendar effects", we take weekly differences, so that we regress $\ln \left(Y_{t+5}\right)-\ln \left(Y_{t}\right)$ on the variable $\ln \left(Y_{t}\right)-\ln \left(Y_{t-5}\right)$ and further lags. However, instead of setting the prior at simply a white noise process or a unit root, we set the prior for the first lag to be .2 , thus allowing some predictability in the first differences, but not a unit root process.

We note, as Hansen (2000) reminds us, that when our forecasting horizon is greater than the sampling interval, so we are building in a moving average process in the error term. Rather than correct the VAR with MA processes, however, we use longer lags to correct for the moving average effects.

\section{In-Sample Results}

The in-sample regression diagnostics for the VAR and BVAR models appear in Table 1. We estimate the model initially for the entire data set. We use the following diagnostics: the multiple correlation coefficient $\left[R^{2}\right]$, the Hannan-Quinn (1979) information criterion [HQIF], the marginal significance of the Ljung-Box (1978) [LB] Q-statistic for serial dependence in the residuals, as well as that marginal significance of the MacLeod-Li (1983) [ML] Q-statistic for serial dependence in the squared residuals, the marginal significance of the Jarque-Bera (1980) $[J B]$ test of normality of residuals and the marginal significance of the Brock-Deckert-Scheinkman (1987) [BDS] test of nonlinear serial dependence in the residuals Finally, the Lee-White-Granger (1992) [LWG] test gives the number of significant regressions of the residuals for 1000 randomly generated nonlinear combinations of regressors. ${ }^{7}$ We present these statistics for the four dependent variables, the weekly logarithmic change in the RMB, $\Delta r m b$, the weekly change in the non-deliverable forward premia, $\Delta n d f$, the weekly change in the interest-rate differentials, $\Delta$ idif $f$, and the weekly change in the logarithm of the Series A share price index, $\Delta s p i$. In both systems, these variables are functions of their own lags as well as the lags of the weekly change in the Euro exchange rate, $\Delta$ euro. We selected a liberal lag length of 13 for all of the variables in order to ensure serial

7 All of these statistical tests are clearly summarized in Franses and van Dijk (2000). 
independence in the regression residuals. The interest differential variable was also used in levels at a one-week forecasting horizon, but the results appeared to be quite robust to the use of levels or first differences.

Table 1 tells us that the overall sample explanatory power, given by the $R^{2}$ and HQIF statistics, is pretty much the same. The liberal lag length has allowed us to accept the null hypothesis of serial independence for both the VAR and BVAR methods, as shown by the $L B$ statistics. However, the VAR still shows traces of serial dependence in the squared residuals, while the BVAR does not, as shown by the $M L$ statistics, while both do not allow us to reject normality in the regression, as indicated by the JB tests. Finally the BDS tests show traces of nonlinear forms of serial dependence for both the VAR and BVAR for the regressions for the $\Delta n d f$ and $\Delta$ idiff $f$ variables, while the LWG tests show little evidence of neglected nonlinearities in all of the equations.

Since the underlying data come from markets undergoing structural change, it is not surprising that the in-sample diagnostics fail to pass some of the specification tests, such as the BDS test, which can be viewed alternatively as a test for model misspecification or a test for nonlinearity [Belaire-Franch and Contreras-Bayarri (2001), p.1] . The overall explanatory power of both models is about the same, but the diagnostics give the edge to the BVAR approach on the basis of the McLeod-Li tests.

Table 2 pictures the in-sample Granger tests of causality. We see that the change in the $\Delta$ euro is significant or a Granger cause of the $\Delta n d f$ in both methods, and that the $\Delta n d f$ is a significant determinant of $\Delta s p i$ in the BVAR method and of the interest differential in both methods. The interest rate differentials respond to changes in the RMB and the $\Delta n d f$, as well as their own lags, but play no role in predicting other variables. The in-sample Granger tests of causality indicate that changes in the value of the Euro affect Chinese markets through the $\Delta n d f$, which in turn affects changes in the share market, while interest rate changes appear to be passive, reacting to changes in these variables but with no apparent feedback effects.

The key Granger P-Values are those linking the $\Delta$ euro with the $\Delta n d f$, and those linking the $\Delta n d f$ with $\Delta$ spi. Figure 5 pictures the bootstrapped distributions of these P-Values, for 1000 experiments, for the BVAR model, following the procedure of Efron (1979) and Efron and Tibshirani (1993). The distributions of bootstrapped $\mathrm{P}$-Values show only a few are insignificant. The percentage of insignificant $\mathrm{P}$-Values for the $\Delta n d f$ with respect to the $\Delta$ euro is $5.5 \%$. However, for the $\Delta s p i$ with respect to the $\Delta n d f$ the percentage is $16.4 \%$. However, at the $10 \%$, level, the percentage of insignificant P-Values is $7.2 \%$.

We picture in Figure 6 the impulse response paths of the $\Delta n d f$ in response to an impulse in the $\Delta$ euro, and the $\Delta s p i$ in response to the $\Delta n d f$. Both impulse response paths are stable. We also picture in Figure 6 the upper and lower bounds at the $10 \%$ level from 1000 bootstraped simulations. The initial effect of the $\Delta$ euro impulse is negative for the $\Delta n d f$; while the impulse to the $\Delta n d f$ is initially positive. The impulse response paths show that the effects disappear within 30 days. 


\section{Out-of-Sample Performance}

\subsection{Competing Models}

We first take up the out-of-sample performance of the two competing methods, the VAR and BVAR approaches. Then we evaluate the performance of the better BVAR model for the out-of-sample Granger test of causality. Table 2 shows the out-of-sample statistics, the root mean squared error measure $(R M S Q)$, the success ratio of correct sign predictions (SR); as well as the P-Values of the DieboldMariano test (DM); the Giamomini-White test (GM); and Clark-West test (CW) for out-of-sample predictive ability of two competing models. The results of these tests appear in Table 3.

We follow the real time forecasting approach of Stock and Watson (1999) for evaluating out-of-sample performance: we split the sample in half, forecast the dependent variables for one period, and obtain the first forecast error of our sample. Then we incorporate this period into our sample, re-estimate the model, and forecast for the next period. We continue this period of one-period sequential forecasting until we exhaust our sample.

Table 3 shows that the RMSQ and SR statistics slightly favor the BVAR model. However, these statistics did not tell us if one model significantly outperforms another model in terms of out-of-sample forecasting performance. The Diebold-Mariano (1995) was the first test for model comparison for out-of-sample forecasting performance. This test takes the out-of-sample forecasting errors of two models, applies a loss function to these errors, such as the absolute value of the errors, and compares the differences in the loss functions of these errors. After correcting for serial dependence in the differences in the loss functions, the test is a standard-normal distribution. Table 3 tells us that the BVAR is a significant improvement over the VAR model for all of the dependent variables.

The Giacomini-White (2004) test is an adaptation of the Diebold-Mariano test, in that it is a test of conditional predictive accuracy. What model does better, conditional on the previous period losses? This test reduces to the Diebold-Mariano test if we are only interested in unconditional predictive accuracy. We see that the conditional GW test shows that the BVAR is significantly better only for the interest differential, $\Delta$ idif $f$. Finally the Clark-West (2004) takes up out-of-sample performance of two competing nested model. This test is appropriate to the extent that the VAR and BVAR models are nested, since the BVAR reduces to a VAR model in the absence of the Bayesian priors. Table 3 shows that the BVAR model outperforms the VAR models at the $10 \%$ level for all of the variables in the Clark-West approach.

The statistics and tests in Table 3 favor strongly, though not unanimously, the BVAR approach over the VAR approach in terms of out-of-sample performance. We will use the BVAR approach for assessing out-of-Sample tests of causality.

\subsection{Granger Tests of Causality}

Chao, Corradi and Swanson (2000) note that in-sample tests of Granger causality, usually done with Ftests, are the common practice. However, they develop an out-of-sample approach based on the one- 
period predictive ability of competing models, one a restricted model and the other an unrestricted model. In this case, the two competing models are nested models.

We are interested in the causal influence of the $\Delta$ euro on the endogenous variables. We see in Table that the out-of-sample tests show even stronger effects: at the $5 \%$ level of significance the $\Delta$ euro is a Granger cause of $\Delta n d f$, and for only a slightly higher P-Value, of $5.6 \%$, it is a Granger cause of the $\Delta s p i$. Table 4 shows that $\Delta n d f$ is a Granger cause of the interest differentials, $\Delta$ idiff , but not of the share market changes, $\Delta s p i$, unlike the in-sample test results. However, the basic message of the out-ofsample tests of Granger causality are broadly the same: changes in the euro strongly affect Chinese markets, both NDF premia and changes in the share price indices. The only difference between the two forms of the Granger test is whether the euro has direct effects on the share price index, or if the effect is indirect, through the NDP premia or discounts.

\section{Conclusion}

We have run the Bayesian autoregressive system under several alternative specifications as well as those discussed above. The results are very robust and very clear. In fact, even the simplest, nonBayesian Vector Autoregression gives very clear and highly significant evidence for the hypothesis formulated in this paper.

The results are surprisingly clear and significant. We summarize them below.

1. The Renminbi NDF is driven by its own dynamics and only by the Euro-Dollar exchange rate. Neither interest rate differentials nor the minor spot exchange rate RMB-US dollar movements influence the Renminbi NDFs.

2. The effect of Euro-US dollar exchange rate is very clear. As Euro appreciates, the Renminbi discount in the NDF market becomes more negative. This result is significant even at $1 \%$ level.

3. The interest rate differentials do not cause changes in the NDF quotes. However, they are affected marginally by stock indices and the NDF itself. Both of these variables affect the interest rate differentials at the $5 \%$ level.

4. As we argued in this paper the US dollar-RMB spot rate does move in a serially correlated fashion and does not appear to be a random walk. There is some information in this variable, in spite of the "peg".

These results are surprisingly robust across various specifications. In fact they get richer when we consider the smoothing effect of the Bayesian priors.

In this paper we outlined a hypothesis that maintained that the Chinese Renminbi NDF movements were driven by speculative psychology generated by the Euro-dollar exchange rate. According to this hypothesis, as the Euro appreciates market players bet on a Yuan revaluation and the NDF discount deepens. The evidence for the hypothesis outlined in this paper is overwhelming, in spite of the short sample of daily data that is available. 


\section{References}

Belaire-Franch, Jorge and Dulce Contreras-Bayarri (2001), "The BDS Test: A Practitioner's Guide," Working Paper: Departamento de Analisis Economico, Universitat de Valencia, downloadable from http://aeser.anaeco.us.es/pdf/dt02-01.

Bergsten, Fred (2004), "Bush Needs to Make a Decisive Change of Course," Financial Times, Dec. $14: 13$.

Brock, W., W. Dechert, and J. Scheinkman (1987),"A Test for Independence Based on the Correlation Dimension," Working Paper, Department of Economics, University of Wisconsin at Madison.

Chao, John, Valentina Corradi, and Norman Swanson (2000), "An Out-of-Sample Test for Granger Causality," Working Paper, Department of Economics, Rutgers University.

Clard, Todd E. and Kenneth D. West (2004), "Using Out-of-Sample Mean Squared-Prediction-Errors to Test the Margingale Difference Hypothesis," Working Paper, Department of Economics, University of Wisconsin.

Diebold, Francis X. and Roberto Mariano (1995), "Comparing Predictive Accuracy,” Journal of Business and Economic Statistics, 3: 253-63.

Dooley, Michael P., David Folkerts-Landau, and Peter M. Garber (2004), "The U.S. Current Account Deficit and Economic Development: Collateral for a Total Return Swap,” NBER Working Paper No. 10727, Cambridge MA: National Bureau of Economic Research.

Efron, B. (1979), “Boostrap Methods: Another Look at the Jackknife,” The Annals of Statistics, 7: 1-26. and R. Tibshirani (1993), An Introduction to the Boot-strap, New York: Chapman and Hall.

Franses, Philip Hans and Dick van Dijk (2000), Non-linear Time Series Models in Empirical Finance, Cambridge: Cambridge University Press.

Giacomini, Raffaella and Halbert White (2004), “Tests of Conditional Predictive Ability," Working Paper, Department of Economics, University of California, Los Angeles.

Hamilton, James D. (1989), "A New Approach to the Economic Analysis of Nonstationary Time Series Subject to Changes in Regime," Econometrica, 57: 357-84.

(1990), "Analysis of Time Series Subject to Changes in Regime," Journal of Econometrics, 45: 39-70.

Hannan, E.J. and B.G. Quinn (1979), "The Determination of the Order of an Autoregression," Journal of the Royal Statistical Society, B(41): 190-95. 
Hansen, Lars P. (2000), “Generalized Methods of Moments: A Time Series Perspective," in International Encyclopedia of the Social and Behavior Sciences, London: Elsevier Science Publishing.

Inoue, Atsushi and Lutz Killian (2004), "On the Selection of Forecasting Models," Working Paper, Department of Economics, University of Michigan.

Jarque, C.M. and A.K. Bera (1980), “Efficient Tests for Normality, Homoskedasticity, and Serial Independence of Regression Residuals," Economics Letters, 6: 255-59.

Lau, Francis, Yik-ko Mo, and Kim-hung Li (2004), "The Impact of a Renminbi Appreciation on Global Imbalances and Intra-Regional Trade," Hong Kong Monetary Authority Quarterly Bulletin, March: 16-31.

Lee, T.H, H. White, and C.W.J. Granger (1992), "Testing for Neglected Nonlinearity in Times Series Models: A Comparison of Neural Network Models and Standard Tests," Journal of Econometrics, 56: 26990.

Litterman, Robert (1986), "Forecasting with Bayesian Vector Autoregressions: Five Years of Experience," Journal of Business and Economic Statistics, 4: 25-38.

Ljung, G.M. and G.E.P. Box (1978), “On a Measure of Lack of Fit of Time Series Models," Biometrica, 65: 297-303.

McLeod, A. I. and W.K. Li (1983), “Diagnostic Checking of ARMA Time Series Models Using SquaredResidual Autocorrelations," Journal of Time Series Analysis, 4: 269-73.

Neftçi, Salih N. (2004), "Financial Engineering of Renminbi Revaluation Bets and Implications for Hong Kong Dollar," downloadable from http://www.neftci.com.

Stock, James H. and Mark W. Watson (1999), "Forecasating Inflation,” Journal of Monetary Economics, 44: 293-335.

Zhang, Peter (2004), Renminbi Derivatives, London: World Scientific Press. 
Table 1. In-Sample Regression Diagnostics Method

\begin{tabular}{lrrrrrrrr}
\hline \multicolumn{7}{l}{ VAR } \\
\multicolumn{7}{l}{ Dependent Variables } \\
& $\Delta r m b$ & $\Delta n d f$ & $\Delta$ Bdiff & $\Delta s p i$ & $\Delta r m b$ & $\Delta n d f$ & $\Delta$ idiff & $\Delta s p i$ \\
\hline$R^{2}$ & .683 & .730 & .661 & .725 & .683 & .730 & .661 & .791 \\
$H Q I F$ & -810 & -802 & -312 & -128 & -809 & -802 & -311 & -128 \\
$L B$ & .888 & .116 & .378 & .397 & .887 & .116 & .379 & .399 \\
$M L$ & .065 & 0 & 0 & 0 & .988 & .987 & .790 & .984 \\
$J B]$ & .883 & .116 & .379 & .399 & .888 & .116 & .378 & .397 \\
$B D S$ & .387 & 0 & .007 & .209 & .390 & 0 & .006 & .758 \\
LWG & 11 & 13 & 4 & 16 & 14 & 12 & 1 & 8 \\
\hline
\end{tabular}

Table 2. Granger Tests of Causality P-Value of F-Statistics Method

\begin{tabular}{|c|c|c|c|c|c|c|c|c|}
\hline & VAR & & & & BVAR & & & \\
\hline & \multicolumn{8}{|c|}{ Dependent Variables } \\
\hline & $\Delta r m b$ & $\Delta n d f$ & $\Delta$ idiff & $\Delta s p i$ & $\Delta r m b$ & $\Delta n d f$ & $\Delta i d i f f$ & $\Delta s p$ \\
\hline \multicolumn{9}{|c|}{ Argument: } \\
\hline$\Delta r m b$ & .000 & .073 & .375 & .227 & .000 & .000 & .000 & .001 \\
\hline$\Delta n d f$ & .458 & .000 & .012 & .115 & .124 & .000 & .000 & .000 \\
\hline$\Delta i d i f f$ & .873 & .064 & .000 & .076 & .872 & .064 & .000 & .076 \\
\hline$\Delta s p i$ & .305 & .715 & .009 & .000 & .305 & .715 & .009 & .000 \\
\hline$\Delta$ euro & .208 & .008 & .596 & .536 & .208 & .008 & .594 & .539 \\
\hline
\end{tabular}

Table 3. Out-of-Sample Forecasting Performance: VAR vs. BVAR Models Method

\begin{tabular}{|c|c|c|c|c|c|c|c|c|}
\hline & VAR & & & & BVAR & & & \\
\hline & Depen & ent Varia & & & & & & \\
\hline & $\Delta r m b$ & $\Delta n d f$ & $\Delta i d i f f$ & $\Delta s p i$ & $\Delta r m b$ & $\Delta n d f$ & $\Delta i d i f f$ & $\Delta s p$ \\
\hline Test: & & & & & & & & \\
\hline$R M S Q$ & $.232 e-4$ & 168.69 & .002 & .015 & $.213 e-4$ & 167.74 & .014 & .009 \\
\hline$S R$ & .650 & .763 & .665 & .812 & .661 & .766 & .812 & .819 \\
\hline$D M$ & - & - & - & & .015 & .0002 & .010 & .061 \\
\hline GW & - & - & - & & .126 & .463 & .002 & .145 \\
\hline$C W$ & - & - & - & & .053 & .062 & .029 & .064 \\
\hline
\end{tabular}


Table 4. Out-of-Sample Granger Causality Tests

\section{BVAR Models}

Test: $\mathrm{H}_{0}: \Delta$ euro does not predict...

\begin{tabular}{lcccc} 
& $\Delta r m b$ & $\Delta n d f$ & $\Delta$ idiff & $\Delta s p i$ \\
CW & .061 & .036 & .082 & .056 \\
Test: $\mathrm{H}_{0}: \Delta n d f$ not predict... & & & & \\
& $\Delta r m b$ & - & $\Delta$ idiff & $\Delta s p i$ \\
$\mathrm{CW}$ & .439 & & .0004 & .206 \\
\hline
\end{tabular}


Figure 1. Daily Reminbi/Dollar Rate, July 2002-July 2004

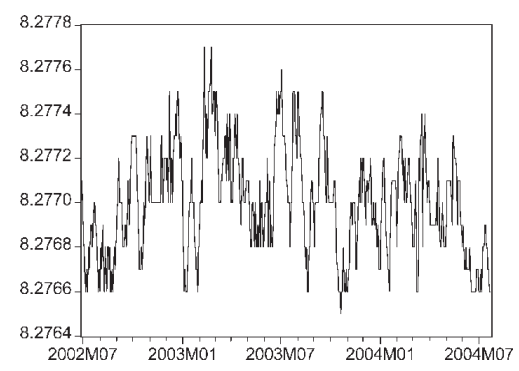

Figure 2.

\section{Chinese - US Interest Differential}

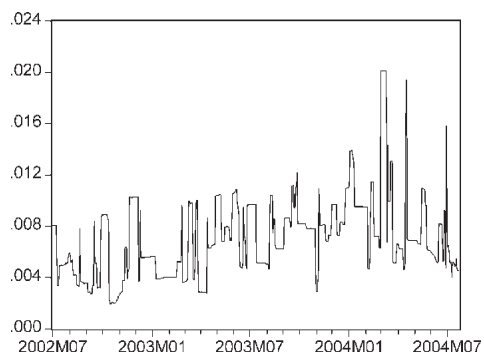

\section{Month Non-deliverable Forward Premia}

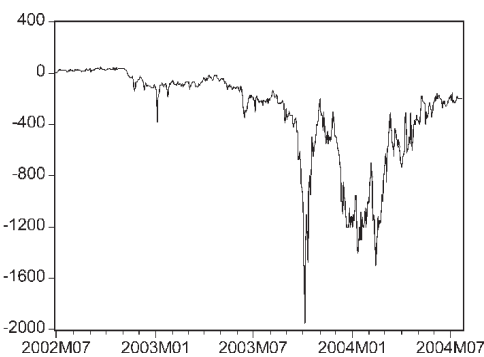

Figure 3.

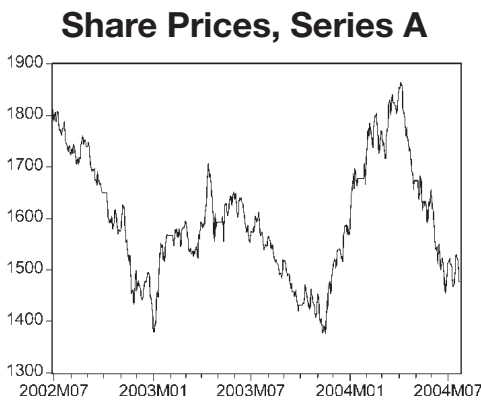

Share Prices, Series B

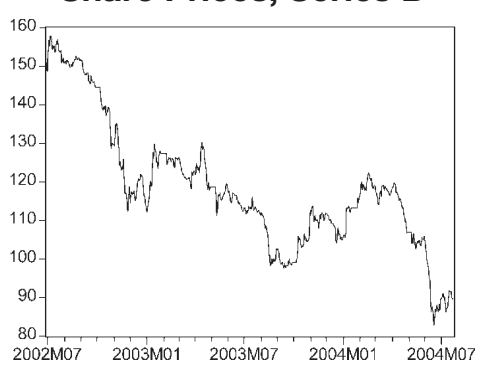


Figure 4. Euro/Dollar Exchange Rate

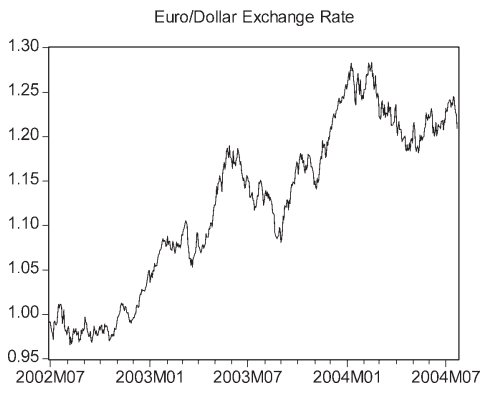

Figure 5. Distribution of P-Values, Granger Tests of Gausality 1000 Bootstrapped Replications
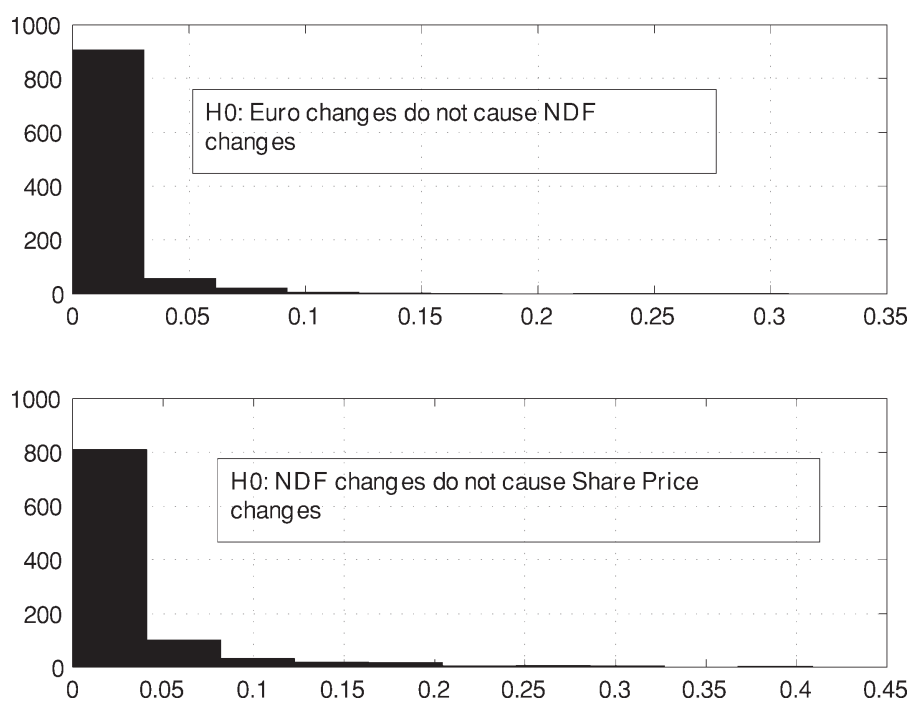

Figure 6.

Impulse Response of NDF to Euro

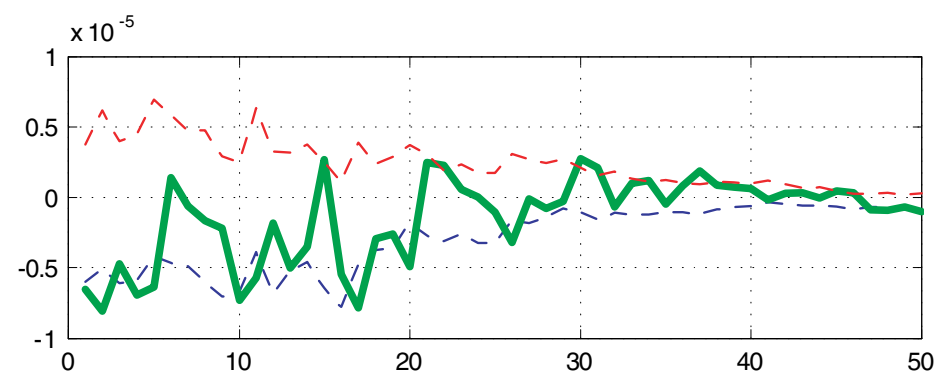

Impulse Response of SPI to NDF

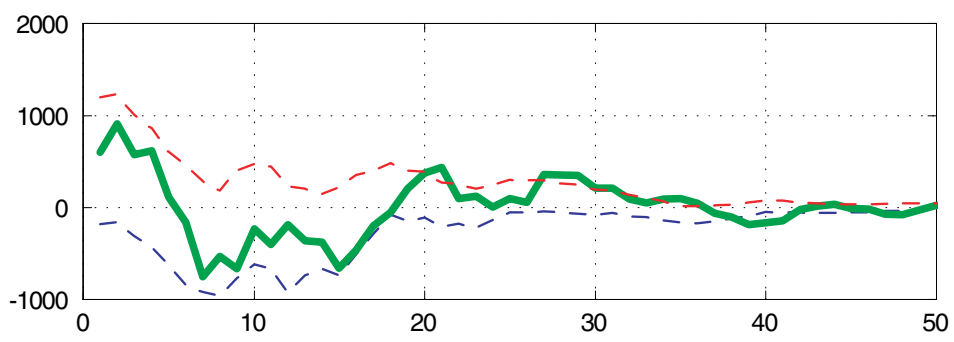

